\title{
Dystonia, Spasticity and Botulinum Toxin Therapy: Rationale, Evidences and Clinical Context
}

\author{
Raymond L. Rosales ${ }^{1,2}$ \\ ${ }^{1}$ Department of Neurology and Psychiatry, \\ University of Santo Tomas and Hospital, Manila, \\ ${ }^{2}$ Center for Neurodiagnostic and Therapeutic Services, \\ Metropolitan Medical Center, Manila, \\ Sections of Neuromuscular and Movement Disorders
}

Philippines

\section{Introduction}

Perhaps among the central nervous system (CNS) conditions with muscle hyperactivity, dystonia and spasticity figure as those that are disabling and requiring therapeutic intervention. Dystonia is a neurological syndrome characterized by sustained muscle contractions usually producing twisting and repetitive movements or abnormal postures. The sustained movements of dystonia may have overlying spasms similar to tremor but have a directional preponderance. Three other important clinical features of dystonia are occurrences of pain, sensory trick phenomenon (i.e. touching "hot spots" in body surface that abolishes the dystonia), and changes in severity depending on activity and posture . Spasticity is typified by a velocity-dependent occurrence of a "catch" following passive limb movement. Recently, the scope of spasticity has been broadened in its definition as a disordered sensori-motor control resulting from an upper motor neuron (UMN) lesion presenting as intermittent or sustained involuntary activation of muscles(1-2) . Although their etiopathogenesis differ, both conditions overlap as regard the following: [a] occurrence of muscle co-contractions; [b] Overactivity involves not only extrafusal but also intrafusal muscles(3-4) [c] Intrinsic muscle changes in size and visceco-elastic properties (5-6); [d] contractures if left unattended (7);[e] muscular spread in synergy, "overflow" and compensatory muscles; [f ] loss of dexterity; [g] occurrence of pain to varying degrees; [h] secondary bone and joint abnormalities; [i] may lead to "compensatory circuitry changes" at segmental and suprasegmental levels (4) ; [j] May lead to posturing and cosmesis issues, and [k] hygiene, quality of life and social impact. Another common thread between dystonia and spasticity is the reduction in muscle tone following botulinum neurotoxin therapy (BoNT), and effectively addressing the disordered sensori-motor control in both conditions. Intuitively, BoNT will be most efficacious in cases with a combination of spasticity and dystonia (i.e. spastic dystonia), such as in childhood spasticity(8). This chapter summarizes the clinical efficacy of BoNT in both dystonia and spasticity. 
Dystonia - The Many Facets

\section{BoNT: Peripheral blockade and beyond}

There are two kinds of BoNT (type A [BoNT-A: onabotulinumtoxinA or Botox ${ }^{\circledR}$, abobotulinumtoxinA or Dysport ${ }^{\circledR}$ and incobotulinumtoxinA or Xeomin ${ }^{\circledR}$ ], and type B [BoNT-B: rimabotulinumtoxin $B$ or Neurobloc ${ }^{\circledR} /$ Myobloc $\left.^{\circledR}\right]$ ) that have been proven to be safe and effective in treating various hyperfunctional cholinergic states. Their therapeutic applications range from various forms of muscle hyperactivity (e.g. dystonia, spasticity, spasms, tremors, and tics), autonomic hyperactivity (e.g. drooling, hyperhidrosis and bladder overactivity) and cosmesis (e.g. frown lines and "crow's feet). BoNT is more effective in blocking active neuromuscular junctions(9), and this effect can be enhanced by electric stimulation of the peripheral nerve(10). This toxin disrupts neurotransmission by cleavage of pre-synaptic vesicle fusion proteins; SNAP-25 for BoNT-A and synaptobrevin for BoNT-B, effectively blocking release of acetylcholine to the neuromuscular junctions and induce chemodenervation. The BoNT-A initially binds presynaptically (via the heavy chain attachment domain) and enters neurons by binding to the synaptic vesicle protein SV2(11). The toxin then undergoes internalization by vesicle endocytosis and translocation into the cytosol, to eventually exert its light chain proteolytic activity(12). After injection, the BoNT complex dissociates and diffuses into the target tissues. Toxin spread is a fast and active phenomenon that is driven by BoNT dose, dilution, needle size, and injection technique among others(13) . Subclinical effects of BoNT on endplates far away from the injected sites can be demonstrated by increased jitter in single-fiber electromyography (SFEMG) in animals(3,14) and humans(15-16). Clinically not relevant for the moment and taken with a cautious stand because of the high animal doses applied, BoNT may undergo retrograde axonal transport, possibly transcytosed to afferent neurons, in which it cleaves its substrate SNAP-25. BoNT-truncated SNAP-25 appears not only at the injection site but also in distant regions that project to the infusion area. This retrograde spread was blocked by colchicine, pointing to a likely involvement of microtubule-dependent axonal transport(17). BoNTalso affects the cholinergically mediated intrafusal fibers of muscle spindles, parallel to that of extrafusal fibers, implying an important functional effect (see a review on the subject by Rosales and Dressler, 2010[4]). In healthy, dystonic or spastic adults, the effect on muscle spindles appear to be more prolonged than that in extrafusal fibers, and whether one applies studies using the tonic vibration reflex (TVR)(18-19); or the transcranial magnetic stimulation(20). Since the gamma-motor-neurons are unable to activate the intrafusal fibers with BoNT-A, the muscle spindle output via the afferent axons will be reduced, and because muscle activity is supported by afferent feedback, there may be reduced alpha-motorneuron drive(3). These events imply that there could be potential modulation of central motor programs following BoNT-A(21). In fact, recent BoNT-A studies in dystonia and spasticity have shown evidences of modifications in the cortical and subcortical levels(2224); including plasticity changes(25).

\section{BoNT for dystonia}

\subsection{Rationale}

Dystonia is a multi-level system disorder where involvement spans from the peripheral (muscular) to the segmental and suprasegmental levels (brainstem, basal ganglia and cortex)(4,26). Muscle hypertonus/spasms in dystonia are relieved by chemodenervation procedures that include muscle-based injections (i.e. muscle afferent block [MAB] and 
BoNT) and near nerve injections (i.e. phenol block). Although useful in near large nerve injections (e.g. obturator and femoral nerves), phenol has not been encouraging because of pain associated with the procedure and its unpredictable response (27). Hinged on the abolition of abnormal muscle spasms with "sensory trick" and MAB in dystonia (i.e. applying TVR[28]), it is believed that the BoNT does have sensory modulatory effects, apart from pure muscle relaxation (see a recent review on the subject by Kanovsky and Rosales[26]). In addition, BoNT-A may reduce pain comorbidity that occur in dystonia (see a recent review by Rawicki and cohorts[29]). The fact that BoNT injections are able to improve an individual's occupational function and quality of life elevates the rationale for its applications. The latter is best exemplified by occupational dystonias (A separate chapter is dedicated to this end). Figure-1 depicts cases of focal hand dystonias with task-specificity and those with complex regional pain syndrome, being prepared for BoNT-A injections.
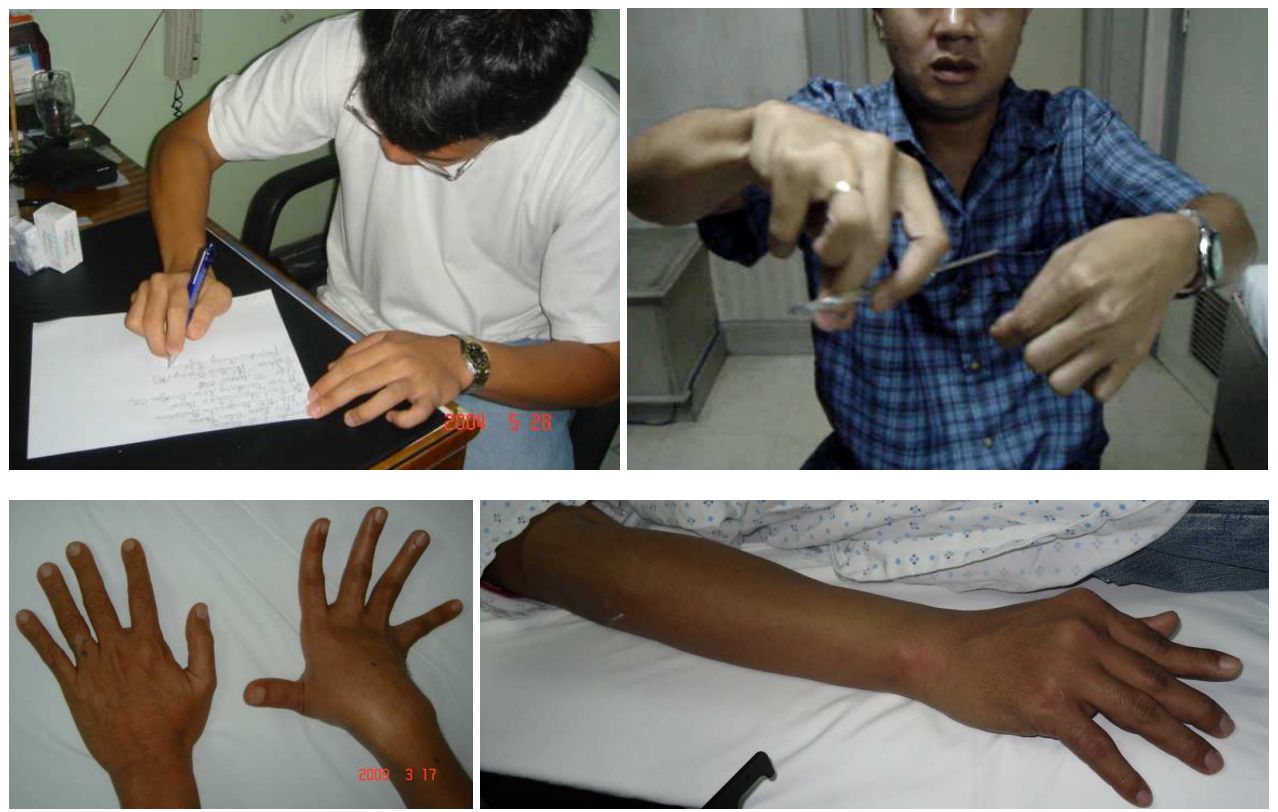

Fig. 1. Focal hand dystonias (upper panel: with task-specificity [Writer's cramp and Barber's cramp]); (lower panel: with complex regional pain syndrome)

\subsection{Evidence-based medicine}

Cochrane reviews summarized the evidences of BoNT superiority as a therapy for blepharospasm(30) and cervical dystonia(31). The American Academy of Neurology (AAN)(32) recommended that BoNT injections should be offered as a treatment option for cervical dystonia (established as effective) and may be offered for blepharospasm, focal upper extremity dystonia, adductor laryngeal dystonia (probably effective). A lower level of evidence was detected for focal lower limb dystonia (possibly effective). According to the European Federation of Neurological Societies [EFNS] version(33), BoNT-A is considered the first-line treatment for primary cranial (except oromandibular) or cervical dystonia; it is 
also effective for writing dystonia; BoNT-B is not inferior to BNT-A in cervical dystonia. Despite the variety of trial formats, virtually all the trials individually, and each outcome measure (objective and subjective) separately, suggested that a single injection cycle of BoNT$A$ is effective and safe for treating cervical dystonia. Enriched trials (using patients previously treated with BoNT-A), suggest that further injection cycles continue to work for most patients. Appropriate injections of BoNT-A into cervical muscles at therapeutic doses are well tolerated, and although adverse effects occur these are transient and rarely severe(31). Furthermore, the available evidence suggests that BoNT-A injections provide more objective and subjective benefits than an anticholinergic drug (i.e. trihexyphenidyl) to patients with cervical dystonia(34).

An international consensus on the aftercare for cervical dystonia and other causes of hypertonia of the neck stated that the benefits following BoNT injection include increased range of movement at the neck for head turning, decreased pain, and increased functional capacity (Class I evidence, level A recommendation). The evidence for efficacy and safety in patients with secondary dystonia in the neck is unclear based on the lack of rigorous research conducted in this heterogeneous population (level $U$ recommendation). Psychometrically sound assessments and outcome measures exist to guide decision-making (Class I evidence, level A recommendation). Much less is known about the effectiveness of therapy to augment the effects of the injection (Class IV, level U recommendation). More research is needed to answer questions about safety and efficacy in secondary neck dystonia, effective adjunctive therapy, dosing and favourable injection techniques(35).

On the issues of BoNT-A application in secondary dystonia as well as for oromandibular dystonia, an applied example is the case of $x$-linked dystonia-partkinsonism (XDP), a type of heredo-degenerative disorder. In the large cohort of oromandibular and lingual dystonias found in XDP, BoNT-A was shown to be safe and effective as one carefully navigates through recommended technical considerations(36). In XDP as well, BoNT-A targeted in cervical and limb dystonias, indicated its superiority over MAB(37). Interestingly, BoNT-A may also be combined with pallidal deep brain stimulation (DBS) in XDP(38), when the former eventually fails as the only treatment, or when toxin doses increase due to body area spread of dystonia, or even in certain instances after DBS .

\subsection{Clinical context}

BoNT is a safe and targeted treatment approach suited for focal dystonia where certain muscles are clearly involved during co-contraction and in which injections can be modified for the changing dystonia patterns, including segmental and overflow muscles involved $(4,13,26)$. Depending upon factors such as muscle bulk, severity of muscle spasm and whether one may want/avoid contiguous muscles in a clinical context, BoNT-A in dystonia may be tailored in certain instances. A "high potency, low dilution" of BoNT-A may best be applied in the cranio-cervical (i.e. injections in the peri-ocular, facial, oromandibular, lingual, laryngeal and neck muscles) and distal limb regions, where BoNT-A is expected to be maximized in a targeted (usually smaller) muscles through 1-2 injection sites, and where spread is best avoided. Whereas, in dystonias of the abdominal, paraspinal, and proximal limb muscles, a "low potency, high dilution" BoNT-A injection protocol could best be applied, since spread may be desirable for very large muscles, when multipoint muscle 
injections is utilized (36). In view of its "dual effects" on the extrafusal and intrafusal muscles, the clinical benefit in practice may "outstrip" the weakness induced by the $\operatorname{BoNT}(4,39)$. Interestingly in cervical dystonia, discrepant and time-related effects vary between relief of muscle hypertonus, associated pain and head posture(31). These findings underscore the BoNT effects far beyond simply blocking muscle spasms in dystonia. For instance, the head posture may be related to muscle spindle changes among other factors $(4)$ and the associated pain relief having perhaps an independent mechanism(29). The role of BoNT-A in pain pathophysiology is beginning to be understood, however, larger studies in neuropathic pain, joint pain, and myofascial pain syndrome are needed to fully ascertain robustness of BoNT therapy in those areas(40-41).

\section{BNT for spasticity}

\subsection{Rationale}

Arguably only one component of UMN, spasticity in both children (e.g. cerebral palsy, see Figure-2) and adults (e.g. post-stroke, traumatic brain/spinal injuries and multiple sclerosis; see Figure-3), may impair one's motor control, quality of life and may eventually lead to economic and care-giver burden. More than one third of patients develop spasticity within
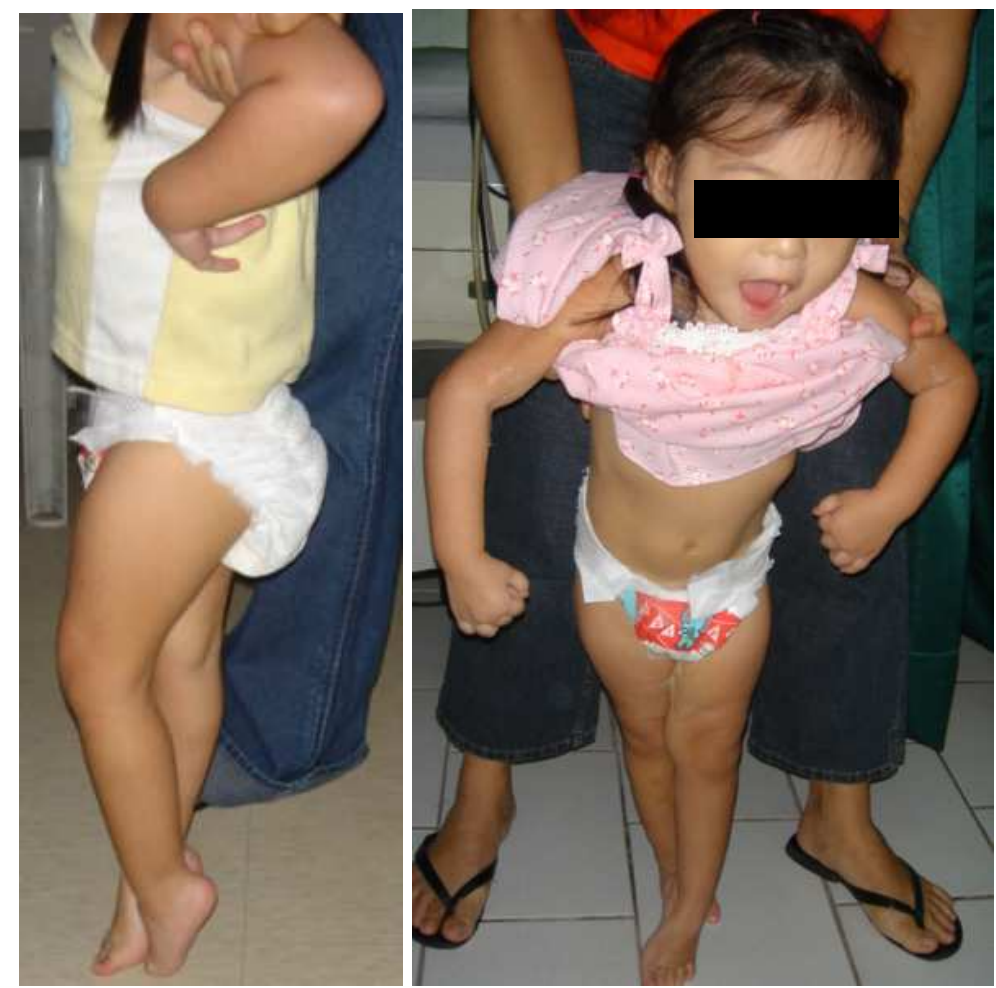

Fig. 2. Childhood spasticity (thigh adductor spasms or "scissoring" and equinovarus foot deformity) 

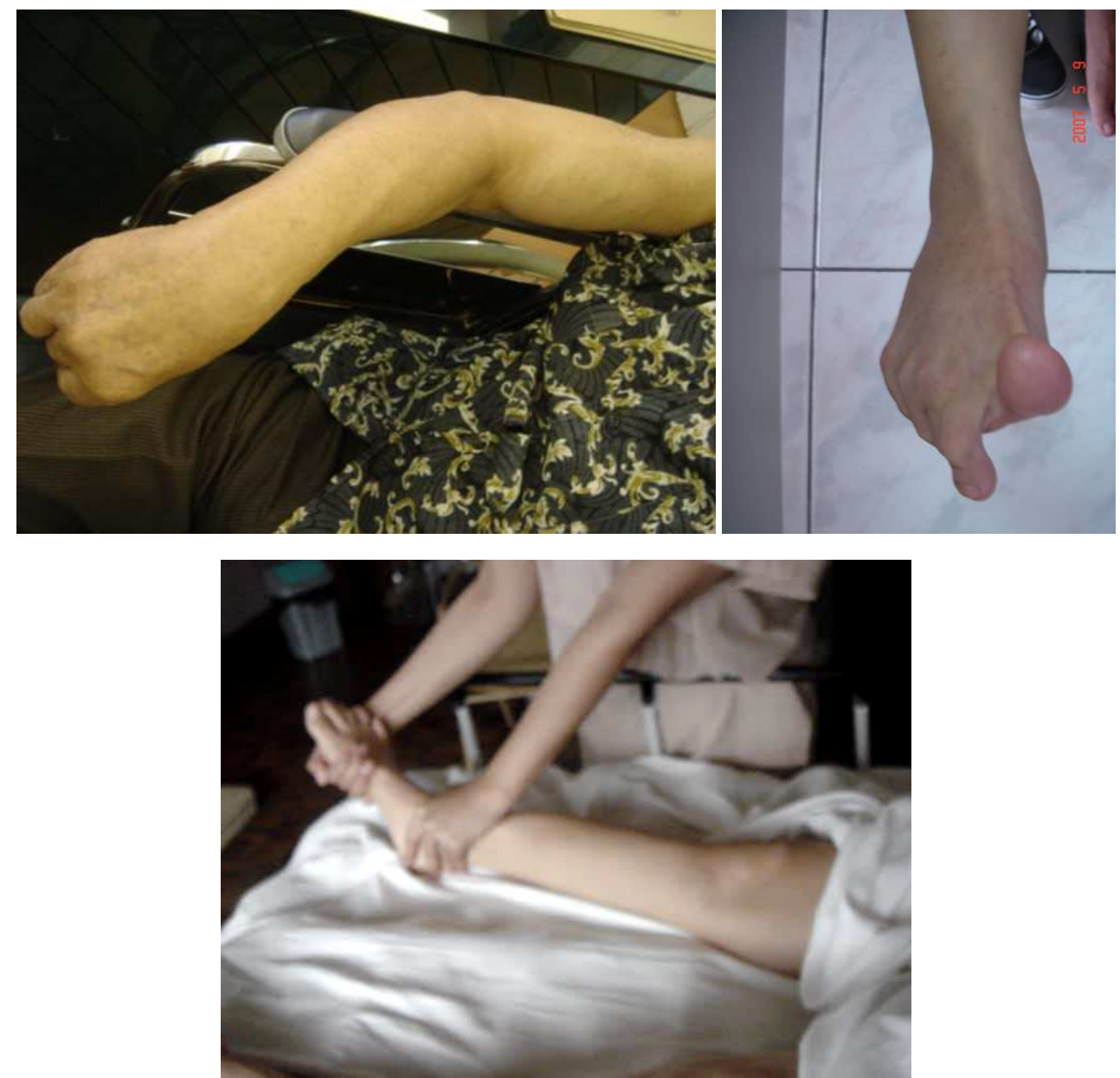

Fig. 3. Spasticity "plus"(Post-stroke with spastic dystonia-left panel; Multiple Sclerosis with spastic dystonia-middle panel; Traumatic brain injury with spasticity and dynamic contracture-right panel)

12 months after stroke(42-43) and a proportion of these patients will develop disabling spasticity requiring intervention(44). Even in the early phases of stroke ("evolving spasticity" [45]) about $19 \%$ of patients(46) or possibly more(47), develop spasticity within 3 months after the ictus. In fact, as many as $80 \%$ of patients without useful functional arm movement after the ictus, develop spasticity (measured by muscle activation recording) within 6 weeks of first stroke(48).

Strokes in the middle cerebral artery region occur in three quarters of patients, hence, the upper limb is affected in a large number of them. In regard to therapeutic intervention, differences may arise between the hemiplegic upper and lower limbs, and these are(49): (a) functional recovery of an arm that enables grasping, holding, and manipulating objects, 
requires the recruitment and complex integration of muscle activity from the shoulder to the fingers. In contrast, a minimal (or less complex) amount of recovery of a hemiplegic leg may be sufficient to obtain functional ambulation; (b) the ability to reach and grasp is a necessary component of many daily life functional tasks, hence reduced upper limb function is likely to reduce independence and increase burden of care. Moreover, muscles in the affected ankle cannot be efficiently recruited in a timely manner to overcome reaching task impairment in stroke patients (50); (c) left uncorrected, secondary complications such as inferior subluxation of the glenohumeral joint, shoulder-hand syndrome, soft tissue lesions, and painful shoulder further hinder rehabilitation of the hemiplegic arm; (d) there is a lack of spontaneous stimulation when performing upper limb functional activities that "assist" in recovery, compared to lower limb activities. Bilateral activity in the legs is often required whenever a patient attempts to transfer, stand or walk, whereas, in performing upper limb activities, the patient may opt to simply use the non-affected side exclusively(51); and, (e) the "protective effect" of spasticity applies more to the lower limbs, and not necessarily for the upper limbs. For example, lower limb spasticity may be beneficial by enabling patients to stand despite the co-occurrence of lower limb weakness. When it does cause harm, however, treatment is required(51-52). Spasticity in the upper limbs (ULS), with these inherent characteristics, may lead to compensatory central nervous system adaptations and changes after stroke such as the "learned non-use" of the affected upper limb. As a form of maladaptive plasticity, the frequent assistance of the non-affected limb may prove to be disadvantageous in the efforts to improve functional recovery(45). Not all patients with ULS will have spasticity-related symptoms (i.e. symptomatic spasticity), but those with functional impairment can be categorized into: (a) those relating to passive function, e.g. hand hygiene, wearing of upper garment, application of splints; (b) pain; (c) associated reaction, and (d) those relating to impaired active function(53). Therefore, it is not unusual that a large majority of BoNT randomized and systematic spasticity intervention studies have been performed on the upper limbs(54). Having its effect in the neural component of spasticity(2,55), the rationale for BoNT-A use is hinged on its reduction of muscle tone via chemodenervation of injected overactive muscles, and potentially prevent, through early injection protocols, eventual complications brought about by the non-neural components (e.g. contracture in spasticity, Fig-3)(45). In fact, BoNT-A is likewise able to address muscle overactivity in spasticity with associated reactions and dystonia (spastic dystonia; Fig-3) (45). The current state of knowledge on the application of BoNT-A in the management of spasticity is depicted in Figure-4.

\subsection{Evidence-based medicine}

Based on meta-analysis derived from well-conducted, randomized controlled clinical trials(54) BoNT-A proved to be safe and efficacious in treating upper and lower limb spasticity, as measured by lowering the Modified Ashworth Score (MAS) that clinically assesses hypertonicity during passive range of motion across a joint(56). A contemporary review on ULS also indicated robust efficacy of BoNT-A, over other pharmacologic therapies(57). Systematic reviews from the AAN (58), Royal College of Physicians (UKRCP)(59), European Consensus (60) and Movement Disorders Society (MDS)(61) lead to formulation of therapeutic guidelines for the application of BoNT-A in the over-all 


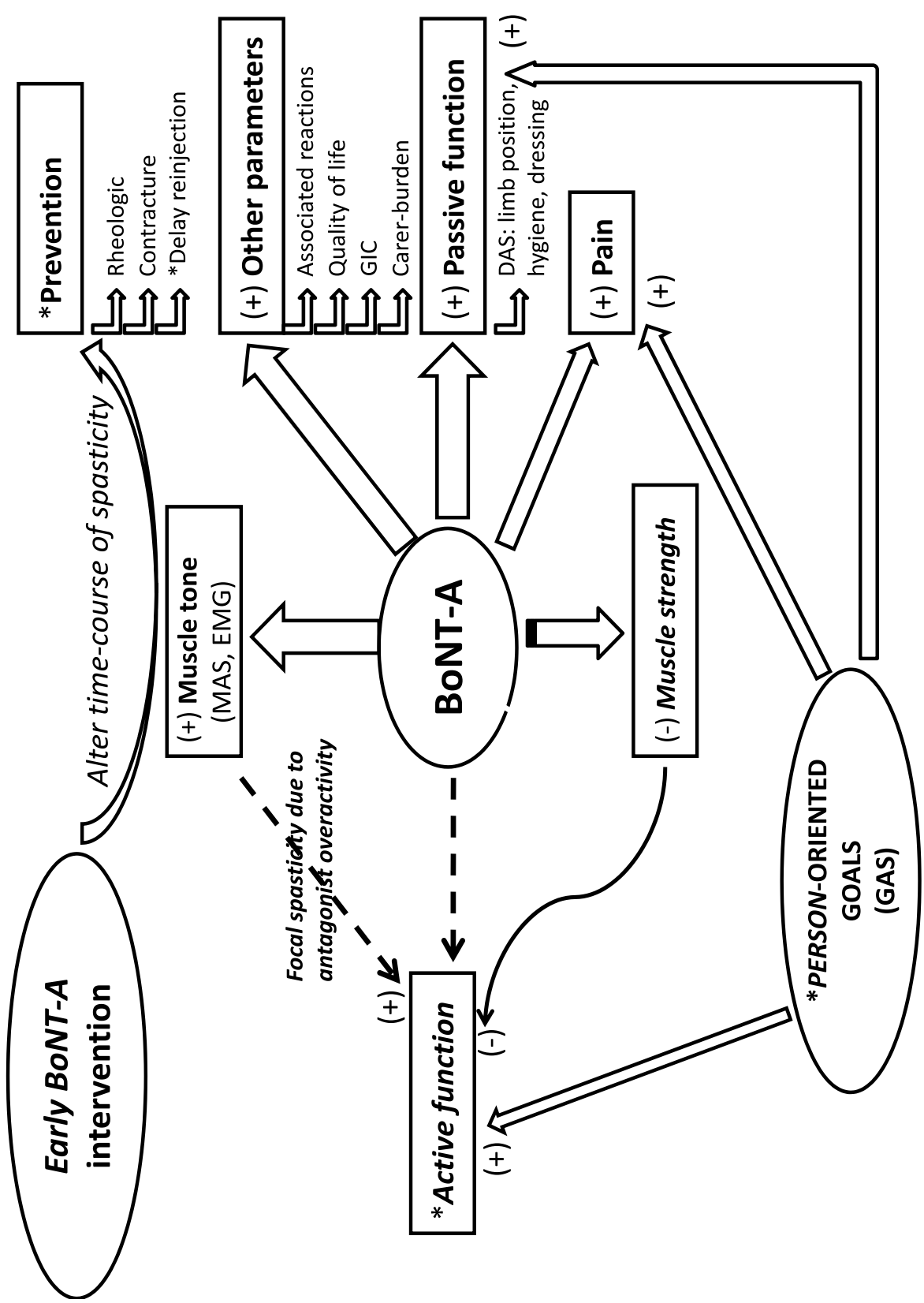

Fig. 4. A schematic diagram on the current state of knowledge on the roles of botulinum neurotoxin injections type A (BoNT-A) in spasticity management; MAS-Modified Ashworth Scale; EMG-Electromyography; GIC-Global impression of change; DAS-Disability Assessment Scale; GAS-Goal Attainment Scaling 
management of spasticity. In parallel, international consensus statements were made on the use of BoNT-A over a wide range of indications for adult and childhood spasticity(62-65). The benefit from BoNT-A is maintained after repeated treatment cycles(66-67) and thus, BoNT-A has been thought to be a first line treatment in focal/multifocal spasticity(68). In addition, BoNT treatment has been shown to improve associated reactions in ULS(69) reduce predetermined disability parameters (including pain) (70-73), reduce carer burden(70,73-74), improve person-centered goals(75) and self-reported efficacy with safety(76). However, efficacy of BoNT-A for improvement of motor control and active functions have not been attained(77). While spasticity is an important component of reduced upper limb function, Shaw and colleagues(71) argue that motor weakness is the most important factor. Likewise, their study did not demonstrate improved active function (despite an improvement in muscle tone in favor of intervention), arguably suggesting that spasticity is of less importance. To date, most of the studies show that BoNT-A injection has been applied in the chronic stage(78-80) (i.e.more than 6 months after stroke; average of 2.5 years) wherein spasticity has been established(45) and wherein non-neural, rheologic changes have set-in. Early intervention with BoNT-A (i.e. less than 3 months post-stroke) has been performed in two Phase II trials (designed to estimate sample sizes)(81-82) and in a Phase III trial(83). The first Phase II study by Cousins and associates(81) indicated some functional recovery at 20 weeks in the groups that received onabotulinumtoxinA, following a subanalysis of patients with no arm function (employing Action Research Arm Test) in the baseline assessment (i.e. 3 weeks post-stroke). Interestingly, the second Phase II study by the German group(82) failed to demonstrate improvement in motor control with the FuglMeyer arm score, despite a reduction in finger flexor stiffness, 6 months after injecting incobotulinumtoxinA. The Asian Botulinum Toxin Clinical Trial Designed for Early PostStroke Spasticity (ABCDE-S) was a Phase III study (83) that demonstrated reduction in muscle tone (MAS) at week 4, and which was sustained to 24 weeks, despite a single cycle, uniform injection of 500units abobotulinumtoxinA. In the latter cohort of patients that enrolled patients $2-12$ weeks post- stroke, significant pain reduction (i.e. weeks 4 and 24) was demonstrated among those that had initial spasticity-related pain, but showed no motor control improvement (using the Motor Assessment Scale).

\subsection{Clinical context}

Spasticity has been shown to inhibit active upper limb function(84) mainly because the prime mover is not fully able to overcome the resistance of the spastic (antagonist) muscle. BoNT-A should be used to address specific functional limitations resulting from focal spasticity (i.e . muscle over-activity confined to one or a group of muscles that contribute to a specific functional problem). However, BoNT-A is not always expected to fully or partially recover lost function, except perhaps when that function has been lost primarily due to antagonist muscle over-activity(59) The effect of BoNT-A on muscle tone and muscle strength is dose-dependent (85). It is therefore important to titrate the dose in patients with an "incomplete" UMN lesion to reduce muscle tone sufficiently without inducing excessive weakness (and loss of function)(86). The appropriate time to initiate BoNT-A therapy in ULS should not be dependent on post- stroke duration, but rather on the goals initially set forth. In established spasticity, treatment should be based on the occurrence of impediments to occupational therapy or physiotherapy, or when the disability has reached a plateau or 
when the disability continues to worsen despite such therapies (62). Predefined goals are ideally smart, achievable and person-centered, in order to optimize BoNT-A effects in areas of muscle tone, pain, active/passive functions, burden of care, cosmesis, among others(87). However, in early BoNT-A injection protocols, when spasticity is evolving, goals are likely different, as these are largely for prevention of contracture or possibly improvement in arm function in the long run. Finally, there are generally a couple of ways for which improvements in function can occur. Pre-morbid movement patterns may be regained first because of true motor recovery, and second, because of the redundancy in the number of degrees of freedom of the body(88). In the latter, actions can be accompanied by substitution of other degrees of freedom for movements of impaired joints. Such alternative movements or motor compensations(89) have also been observed in primates recovering from experimental stroke(90). Therefore, targeting specific muscle groups with BoNT-A, without affecting others, has the theoretical potential to unmask selective voluntary movement in situations where this is over-ridden by mass patterns of spasticity in antagonistic muscle groups(91). This underscores the interaction and complexity of proper (or improper) selection/targeting and accidental (or intentional) spread in achieving treatment goals. Last but not least, BoNT should not be administered alone, and its effects are best optimized in concert with a good rehabilitation program and an inter-disciplinary team.

\section{Conclusion}

Backed by robust clinical trials, we have undoubtedly reached a stage where the roles of BoNT in the management of dystonia and spasticity have been historically etched. This is paralleled by a BoNT safety profile that withstood the test of time over 20 years of application in hypertonic muscular disorders. The clinician is placed in a state to choose the best individualized approach to patients with dystonia and spasticity, bearing in mind that for BoNT, the evidences exist, as one negotiates through management issues related to benefit, harm and cost.

\section{Acknowledgment}

Michelle Joya-Tanglao, PTRP, provided bibliography search support and assisted in the manuscript preparation. The CNS staff of Metropolitan Medical Center (Manila) were behind the author in every stage of this chapter preparation.

\section{References}

[1] Pandyan AD, Gregoric M, Barnes MP, Wood D, Van Wijck F, Burridge J, et al. Spasticity: clinical perceptions, neurological realities and meaningful measurement. Disabil Rehabil. 2005;27:2-6.

[2] Esquenazi A, Novak I, Sheean G, Singer BJ, Ward AB. International consensus statement for the use of botulinum toxin treatment in adults and children with neurological impairments-introduction. Eur J Neurol. 2010;17 Suppl 2:1-8.

[3] Rosales RL, Arimura K, Takenaga S, Osame M. Extrafusal and intrafusal muscle effects in experimental botulinum toxin-A injection. Muscle Nerve. 1996;19:488-96

[4] Rosales RL, Dressler D. On muscle spindles, dystonia and botulinum toxin. Eur J Neurol. 2010;17 Suppl 1:71-80. 
[5] Lieber RL, Steinman S, Barash IA, Chambers H. Structural and functional changes in spastic skeletal muscle. Muscle Nerve 2004;29:615-27.

[6] Welmer AK, Widen HL, Sommerfeld DK. Location and severity of spasticity in the first 1-2 weeks and at 3 and 18 months after stroke. Eur J Neurol 2010;17:720-5.)

[7] O'Dwyer NJ, Ada L, Neilson PD. Spasticity and muscle contracture following stroke. Brain 1996;119:1737-49).

[8] Lukban MB, Rosales RL, Dressler D. Effectiveness of botulinum toxin A for upper and lower limb spasticity in children with cerebral palsy: a summary of evidence. J Neural Transm. 2009;116:319-31.

[9] Hallett M, Glocker FX, Deuschl G. Mechanism of action of botulinum toxin. Ann Neurol. 1994;36:449-50.

[10] Eleopora R, Tugnoli V, De Grandis D. The variability in the clinical effect induced by botulinum toxin type A: the role of muscle activity in humans. Mov Disord. 1997;12:89-94.

[11] Dong M, Yeh F, Tepp W, Dean C, Johnson EA, Janz R, et al. SV2 is the protein receptor for botulinum neurotoxin A. Sci Exp. 2006;312:592-6.

[12] Rossetto O, Morbiato L, Caccin P, Rigoni M, Montecucco C. Presynaptic enzymatic neurotoxins. J Neurochem. 2006;97: 1534-45.

[13] Pickett A, Rosales RL. New trends in the science of botulinum toxin-A as applied in dystonia. Int J Neuroscience. 2011;121:22-34.

[14] Rosales RL, Bigalke H, Dressler D. Pharmacology of botulinum toxin: differences between type A preparations. Eur J Neurol. 2006;13 Suppl 1:2-10.

[15] Garner CG, Straube A, Witt TN, Oertel WH. Time course of distant effects of local injections of botulinum toxin. Mov Disord. 1993;8:33-7.

[16] Rosales RL, Arimura K, Gamez G, Osame M. X-linked dystonia-parkinsonism: botulinum toxin therapy and stimulation single-fiber electromyography. Electroencephalogr Clin Neurophysiol. 1995;97 Suppl:S234-5.

[17] Antonucci F, Rossi C, Gianfranceschi L, Rossetto O, Caleo M. Long distance retrograde effects of botulinum neurotoxin A. J Neurosci. 2008;28:3689-96.

[18] Trompetto C, Curra A, Buccolieri A, Suppa A, Abbruzzese G, Berardelli A. Botulinum toxin changes intrafusal feedback in dystonia: a study with the tonic vibration reflex. Mov Disord. 2006;21:777-82.

[19] Trompetto C, Bove M, Avanzino L, Francavilla G, Berardelli A, Abbruzzese G. Intrafusal effects of botulinum toxin in post-stroke upper limb spasticity. Eur J Neurol. 2008;15:367-70.

[20] Kim D, Oh B, Paik N. Central effect of botulinum toxin type A in humans. Int J Neurosci. 2006;116:667-80.

[21] Curra A, Trompetto C, Abbruzzese G, Berardelli A. Central effects of botulinum toxin A. Evidence and supposition. Mov Disord. 2004;19 Suppl 8:S60-4.

[22] Senkarova Z, Hlustik P, Otruba P, Herzig R, Kanovsky P. Modulation of cortical activity in patients suffering from upper arm spasticity following stroke and treated with Botulinum Toxin A: an fMRI study. J Neuroimaging. 2009;20:9-15.

[23] Opavsky R, Hlustik P, Otruba P, Kanovsky P. Sensorimotor network in cervical dystonia and the effect of botulinum toxin treatment: a functional MRI study. J Neurol Sci. 2011;306:71-5. 
[24] Dresel C, Bayer F, Castrop F, Rimpau C, Zimmer C, Haslinger B. Botulinum Toxin Modulates Basal Ganglia But Not Deficient Somatosensory Activation in Orofacial Dystonia. Mov Disord. 2011;DOI:10.1002/mds.23497.

[25] Kojovic M, Caronni A, Bologna M, Rothwell JC, Bhatia KP, Edwards MJ . Botulinum toxin injections reduce associative plasticity in patients with primary dystonia. Mov Disord. 2011;DOI: 10.1002/mds.23681.

[26] Kanovský P, Rosales RL. Debunking the pathophysiological puzzle of dystonia: with special reference to botulinum toxin therapy. Parkinsonism Rel Disord. 2011;17:S11-4.

[27] Massey JM. Electromyography-guided chemodenervation with phenol in cervical dystonia (Spasmodic torticollis). In: Brin MF, Jankovic J, Hallett M, editors. Scientific and Therapeutic Aspects of Botulinum Toxin. Philadelphia, PA: Lippincott, Williams \& Wilkins; 2002.

[28] Kaji R, Rothwell JC, Katayama M, Ikeda T, Kubori T, Kohara N, et al. Tonic vibration reflex and muscle afferent block in writer's cramp. Ann Neurol. 1995;38:155-62.

[29] Rawicki B, Sheean G, Fung VSC, Goldsmith S, Morgan C, Novak I. Botulinum toxin assessment, intervention and aftercare for paediatric and adult niche indications including pain: international consensus statement. Eur J Neurol. 2010;17:S122-34.

[30] Costa J, Espirito-Santo C, Borges A, Ferreira JJ, Coelho M, Moore P, et al. Botulinum toxin type A therapy for blepharospasm. Cochrane Database Syst Rev. 2005;CD004900.

[31] Costa J, Espírito-Santo CC, Borges AA, Ferreira J, Coelho MM, Moore P, et al. Botulinum toxin type A therapy for cervical dystonia. Cochrane Database Sys Rev. 2005;Issue 1. Art.No.:CD003633.

[32] Simpson DM, Blitzer A, Brashear A, Comella C, Dubinsky R, Hallett M, et al. Assessment: botulinum neurotoxin for the treatment of movement disorders (an evidence-based review): report of the Therapeutics and Technology Assessment Subcommittee of the American Academy of Neurology. Neurology. 2008;70(19):1699-1706.

[33] Albanese A, Asmus F, Bhatia KP, Elia AE, Elibol B, Filippini G, et al . EFNS guidelines on diagnosis and treatment of primary dystonias. Eur J Neurol. 2010;doi:10.1111/j.1468-1331.2010.03042.x.

[34] Costa J, Espírito-Santo CC, Borges AA, Moore P, Ferreira J, Coelho MM, et al. Botulinum toxin type A versus anticholinergics for cervical dystonia. Cochrane Database Sys Rev. 2005; Issue 1. Art. No.: CD004312.DOI: 10.1002/14651858.CD004312.pub2.

[35] Novak I, Campbell L, Boycec M, Fung VSC. Botulinum toxin assessment, intervention and aftercare for cervical dystonia and other causes of hypertonia of the neck: international consensus statement. Eur J of Neurol. 2010;17:S94-108.

[36] Rosales RL , Ng AR, Delos Santos MM, Fernandez HH. The broadening application of chemodenervation in $x$-linked dystonia-parkinsonism (part II): an open-label experience with botulinum toxin-A (Dysport ${ }^{\circledR}$ ) injections for oromandibular, lingual, and truncal-axial dystonias. Int J Neuroscience. 2011;21:44-56.

[37] Rosales RL, Delos Santos MM, Ng AR, Teleg R, Dantes M, Lee LV, et al. The broadening application of chemodenervation in $x$-linked dystonia-parkinsonism (part I): muscle afferent block versus botulinum toxin- $\mathrm{A}$ in cervical and limb dystonias. Int $\mathrm{J}$ Neuroscience. 2011;121:35-43. 
[38] Aguilar J, Vesagas TS, Jamora RD, Teleg R, Ledesma L, Rosales RL, at al. The promise of deep brain stimulation in $\mathrm{x}$-linked dystonia parkinsonism. Int J Neuroscience. 2011;121:57-63.

[39] Hallett M. Effects of botulinum toxin at the neuromuscularjunction. In: Brin MF, Jankovic J, Hallett M, editors. Scientific and Therapeutic Aspects of Botulinum Toxin. Philadelphia, PA: Lippincott, Williams \& Wilkins; 2002.p.167-70.

[40] Qerama E, Fuglsang-Frederiksen A, Jensen T. The role of botulinum toxin in management of pain: an evidence based review. Curr Opin Anaesthesiol. 2010;23:602-610.

[41] Finnerup N, Sindrup S, Jensen T. The evidence for pharmacological treatment of neuropathic pain. Pain. 2010;150: 573-81.

[42] Watkins CL, Leathley MJ, Gregson JM, Moore AP, Smith TL, Sharma AK. Prevalence of spasticity post stroke. Clin Rehabil. 2002;16:515-22.

[43] Leathley MJ, Gregson JM, Moore AP, Smith TL, Sharma AK, Watkins CL. Predicting spasticity after stroke in those surviving to 12 months. Clin Rehabil. 2004;18:438-43.

[44] Lundström E, Terént A, Borg J. Prevalence of disabling spasticity 1 year after first-ever stroke. Eur J Neurol. 2008;15:533-9.

[45] Rosales RL, Kanovsky P, Fernandez HH. What's the "catch" in upper-limb post-stroke spasticity: Expanding the role of botulinum toxin applications. Parkinsonism and Rel Disord. 2011;17: S3-10.

[46] Sommerfeld DK, Eek EU, Svensson AK, Holmqvist LW, von Arbin MH. Spasticity after stroke: its occurrence and association with motor impairments and activity limitations. Stroke. 2004;35:134-9.

[47] Lao A, Rosales RL, Po P, Salazar G, Reyes RV, Magsino R, et al. Spasticity among stroke patients: time of occurrence and predictive factors. Neurorehabil Neural Repair. 2008;22:207.

[48] Malhotra S, Cousins E, Ward A, Day C, Jones P, Roffe C, et al. An investigation into the agreement between clinical, biomechanical and neurophysiological measures of spasticity. Clin Rehabil. 2008;22:1105-15.

[49] Feys HM, De Weerdt WJ, Selz BE, Cox Steck GA, Spichiger R, Vereeck LE, et al. Effect of a therapeutic intervention for the hemiplegic upper limb in the acute phase after stroke: A single blind, randomized, controlled multicenter trial. Stroke. 1998;29:785-92.

[50] Hsu WL, Yang YR, Hong CT, Wang RV. Ankle muscle activation during functional reach in hemi-paretic and healthy subjects. Am J Phys Med Rehabil. 2005;84(10):749-55.

[51] Hyman N, Barnes M, Bhakta B, Cozens A, Bakheit M, Kreczy-Kleedorfer B, et al. Botulinum toxin (Dysport $\AA$ ) treatment of hip adductor spasticity in multiple sclerosis: a prospective, randomised, double-blind, placebo controlled dose ranging study. J Neurol Neurosurg Psychiatry. 2000;68:707-12.

[52] Ward AB. A summary of spasticity management - a treatment algorithm. Eur J Neurol. 2002;1 Suppl 1:S48-52

[53] Kong KH, Chua KSG, Lee J. Symptomatic upper limb spasticity in patients with chronic stroke attending a rehabilitation clinic: frequency, clinical correlates and predictors. Rehabil Med. 2010;42:453-7.

[54] Rosales RL, Chua-Yap AS. Evidence based systematic review on the efficacy and safety of BoNT-A in post-stroke spasticity. J Neural Transm. 2008;115(4): 617-23. 
[55] Alhusaini A, Crosbie J, Shepherd R, Dean C, Scheinberg A . No change in calf muscle passive stiffness after botulinum toxin injection in children with cerebral palsy. Dev Med Child Neurol. 2011;53:553-8.

[56] Bohannon RW, Smith MB. Inter rater reliability of a modified Ashworth scale of muscle spasticity. Phys Ther . 1987;67:206-7.

[57] Olvey EL, Armstrong EP, Grizzle AJ. Contemporary pharmacologic treatments for spasticity of the upper limb after stroke: a systematic review. Clin Ther. 2010;32:2282-303.

[58] Simpson DM, Gracies JM, Graham HK, Miyasaki JM, Naumann M, Russman B, et al. Botulinum neurotoxin for the treatment of spasticity (an evidence based review): report of the Therapeutics and Technology Assessment Subcommittee of the American Academy of Neurology. Neurology. 2008;70:1691-8.

[59] Turner-Stokes L, Ashford S, Bhakta B, Heward K, Moore AP, Robertson A, et al. Spasticity in adults: management using botulinum toxin: national guidelines. London: Royal College of Physicians 2009.

[60] Wissel J, Ward AB, Erztgaard P, Bensmail D, Hecht MJ, Lejeune TM, et al. European consensus table on the use of botulinum toxin type A in adult spasticity. J Rehabil Med. 2009;4:113-25.

[61] Elia AE, Filippini G, Calandrella D, Albanese A. Botulinum neurotoxins for post-stroke spasticity in adults: A systematic review. Mov Disord. 2009;24:801-12.

[62] Sheean G, Lannin NA, Turner-Stokes L, Rawicki B, Snow BJ. Botulinum toxin assessment, intervention and after-care for upper limb hypertonicity in adults: international consensus statement. Eur J Neurol. 2010;17:74-93.

[63] Olver J, Esquenazi A, Fung VSC, Singer BJ, Ward AB. Botulinum toxin assessment, intervention and aftercare for lower limb disorders of movement and muscle tone in adults: international consensus statement. Eur J Neurol. 2010;17 Suppl 2: 57-73.

[64] Fehlings D, Novak I, Berweck S, Hoare B, Stott NS, Russo RN. Botulinum toxin assessment, intervention and follow-up for paediatric upper limb hypertonicity: international consensus statement. Eur J Neurol. 2010;17 Suppl 2: 38-56.

[65] Love SC, Novak I, Kentish M, Desloovere K, Heinen F, Molenaers G, et al. Botulinum toxin assessment, intervention and after-care for lower limb spasticity in children with cerebral palsy: international consensus statement. Eur J Neurol. 2010;17 Suppl 2: 9-37.

[66] Bakheit AMO, Fedorova NV, Skoromets AA, Timerbaeva SL, Bhakta BB, Coxon L. The beneficial antispasticity effect of botulinum toxin type $A$ is maintained after repeated treatment cycles. J Neurol Neurosurg Psychiatry. 2004;75: 1558-61.

[67] Lagalla G, Danni M, Reiter F, Ceravolo MG, Provinciali L. Post-stroke spasticity management with repeated botulinum toxin injections in the upper limb. Am J Phys Med Rehabil. 2000;79:377-84.

[68] Sheean G. Botulinum toxin should be first-line treatment for poststroke spasticity. J Neurol Neurosurg Psychiatry. 2009;80:359.

[69] Bhakta BB, O'Connor RJ, Cozens JA. Associated reactions after stroke: a randomized controlled trial of the effect of botulinum toxin type A. J Rehabil Med. 2008;40(1):36-41. 
[70] Brashear A, Gordon MF, Elovic E, Kassicieh VD, Marciniak C, Do M, et al. Intramuscular injection of botulinum toxin for the treatment of wrist and finger spasticity after stroke. N Eng J Med. 2002;347:395-400.

[71] Shaw LC, Price CI, van Wijck FM, Shackley P, Steen N, Barnes MP, et al. Botulinum toxin for the upper limb after stroke (BoTULS) trial: effect on impairment, activity limitation, and pain. Stroke. 2011;42:1371-9.

[72] Kaji R, Osako Y, Suyama K, Maeda T, Uechi Y, Iwasaki M, et al. Botulinum toxin type A in post-stroke upper limb spasticity. Curr Med Res Opin. 2010;26:1983-92.

[73] Kanovsky P, Slawek J, Denes Z, Platz T, Sassin I, Comes G, et al. Efficacy and safety of botulinum neurotoxin NT 201 in poststroke upper limb spasticity. Clin Neuropharmacol. 2009;32:259-65.

[74] Bhakta BB, Cozens JA, Chamberlain MA, Bamford JM. Impact of botulinum toxin type a on disability and carer burden due to arm spasticity after stroke: a randomised double blind placebo controlled trial. J Neurol Neurosurg Psychiatry. 2000;69: 217-21.

[75] McCrory P, Turner-Stokes L, Baguley IJ, De Graaff S, Katrak P, Sandanam J, et al. Botulinum toxin A for treatment of upper limb spasticity following stroke: a multicentre randomized placebo-controlled study of the effects on quality of life and other person-centred outcomes. J Rehabil Med. 2009;41: 536-44.

[76] Muller F, Cugy E, Ducerf C, Delleci C, Guehl D, Joseph PA, et al. Of botulinum toxin for adult spasticity in current clinical practice: a prospective observational study. Clin Rehabil. 2011;DOI: 10.1177/0269215511412799.

[77] Shaw L, Rodgers H, Price C, van Wijck F, Shackley P, Steen N. et al. BoTULS: a multicentre randomised controlled trial to evaluate the clinical effectiveness and cost-effectiveness of treating upper limb spasticity due to stroke with botulinum toxin type A. Health Technol Assess. 2010;14(26).

[78] Kreisel SH, Bazner H, Hennerici MG. Pathophysiology of stroke rehabilitation: temporal aspects of neuro-functional recovery. Cerebrovasc Dis. 2006; 21:6-17.

[79] Kreisel SH, Hennerici MG, Bazner H. Pathophysiology of stroke rehabilitation: the natural course of clinical recovery, use-dependent plasticity and rehabilitative outcome. Cerebrovasc Dis. 2007;23:243-55.

[80] Ozcakir S, Sivrioglu K. Botulinum toxin in poststroke spasticity. Clin Med Res. 2007;5:132-8.

[81] Cousins E, Ward A, Roffe C, Rimington L, Pandyan A. Does low-dose botulinum toxin help the recovery of arm function when given early after stroke? A phase II randomized controlled pilot study to estimate effect size. Clin Rehabil. 2010;24: 501-13.

[82] Hesse S, Mach H, Fro hlich S, Behrend S, Werner C, Melzer I. An early botulinum toxin A treatment in subacute stroke patients may prevent a disabling finger flexor stiffness six months later: a randomized controlled trial. Clin Rehabil. 2011;DOI: $10.1177 / 0269215511421355$.

[83] Rosales RL, He KK, Goh KJ, Kumthornthip W, Mok VCT, Delgado-De Los Santos MM, MD, Chua KSG, Abdullah SJF, Zakine B, Maisonobe P, Magis A, Wong KSL. Botulinum toxin injection for hypertonicity of the upper extremity within 12 weeks after stroke: A randomized controlled trial. Neurorehabil Neural Repair, in press

[84] Mizrahi EM, Angel RW. Impairment of voluntary movement by spasticity. Ann Neurol. 1979;5:494-5. 
[85] Sloop RR, Escutin RO, Matus JA, Cole BA, Peterson GW. Dose-response curve of human extensor digitorum brevis muscle function to intramuscularly injected botulinum toxin type A. Neurology. 1995;46:1382-6.

[86] Bakheit AMO, Zakine B, Maisonobe P, Aymard C, Fheodoroff K, Hefter H, et al. The profile of patients and current practice of treatment of upper limb muscle spasticity with botulinum toxin type a: an international survey. Int $\mathrm{J}$ Rehabil Res. 2010;33(3):199-204.

[87] Turner-Stokes L. Goal attainment scaling and its relationship with standardized outcome measures: a commentary. J Rehabil Med. 2011;43:70-2.

[88] Bernstein NA. The coordination and regulation of movements. Oxford: Pergamon Press; 1967.

[89] Cristea MC, Levin MF. Compensatory Strategies for Reaching in Stroke. Brain. 2000;123(5):940-53.

[90] Friel KM, Nudo RJ. Recovery of motor function after cortical injury in primates: compensatory movement patterns used during rehabilitative training. Somatosensory and Motor Research 1998;15(3):173-89.

[91] Esquenazi A, Mayer N. Botulinum toxin for the management of muscle overactivity and spasticity after stroke. Curr Atheroscler Rep. 2001;3:295-8. 


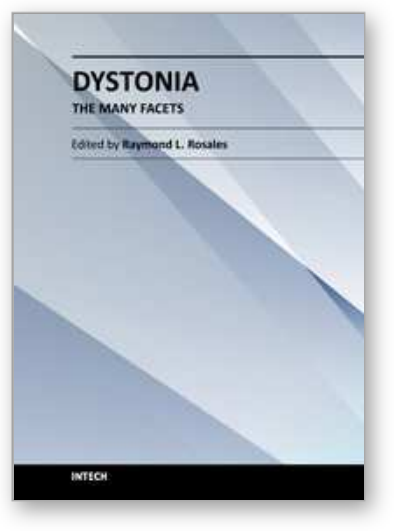

\author{
Dystonia - The Many Facets \\ Edited by Prof. Raymond Rosales
}

ISBN 978-953-51-0329-5

Hard cover, 220 pages

Publisher InTech

Published online 14, March, 2012

Published in print edition March, 2012

Dystonia has many facets, and among those, this book commences with the increasingly associated genes identified, including a construct on how biology interacts with the dystonia genesis. The clinical phenomenology of dystonia as approached in the book is interesting because, not only were the cervical, oromandibular/lingual/laryngeal, task-specific and secondary dystonias dealt with individually, but that the associated features such as parkinsonism, tremors and spasticity were also separately presented. Advances in dystonia management followed, and they ranged from dopaminergic therapy, chemodenervation, surgical approaches and rehabilitation, effectively complementing the approach in dystonia at the clinics. A timely critical pathophysiologic review, including the muscle spindle involvement in dystonia, is highlighted at the book's end.

\title{
How to reference
}

In order to correctly reference this scholarly work, feel free to copy and paste the following:

Raymond L. Rosales (2012). Dystonia, Spasticity and Botulinum Toxin Therapy: Rationale, Evidences and Clinical Context, Dystonia - The Many Facets, Prof. Raymond Rosales (Ed.), ISBN: 978-953-51-0329-5, InTech, Available from: http://www.intechopen.com/books/dystonia-the-many-facets/dystonia-spasticity-andbotulinum-toxin-therapy-rationale-evidences-and-clinical-context

\section{INTECH}

open science | open minds

\author{
InTech Europe \\ University Campus STeP Ri \\ Slavka Krautzeka 83/A \\ 51000 Rijeka, Croatia \\ Phone: +385 (51) 770447 \\ Fax: +385 (51) 686166 \\ www.intechopen.com
}

\author{
InTech China \\ Unit 405, Office Block, Hotel Equatorial Shanghai \\ No.65, Yan An Road (West), Shanghai, 200040, China \\ 中国上海市延安西路65号上海国际贵都大饭店办公楼 405 单元 \\ Phone: +86-21-62489820 \\ Fax: +86-21-62489821
}


(C) 2012 The Author(s). Licensee IntechOpen. This is an open access article distributed under the terms of the Creative Commons Attribution 3.0 License, which permits unrestricted use, distribution, and reproduction in any medium, provided the original work is properly cited. 